\title{
The progress of the environment in Peru: Design of a computer system for bottle recycling applied in shopping centers
}

\author{
Alexi Delgado ${ }^{1}$, Jerson Misael Lazo Amado ${ }^{2}$ \\ ${ }^{1}$ Mining EngineeringSection, Pontificia Universidad Católica del Perú, Lima-Peru, kdelgadov@ pucp.edu.pe \\ ${ }^{2}$ Systems EngineeringProgram, Universidad de Ciencias y Humanidades, Lima-Peru, jerlazoa@uch.pe
}

\begin{abstract}
In this work, the aim is to explore the main problem in Peru, environmental pollution. The methodology used is Balsamiq Mockups, a prototype of web or mobile design. Regarding the case study, we will show the web design, the mobile application and the development of the prototype. Thus, the results of the initial days of launching the application in the respective shopping centers will be shown along with details of the daily benefit of recycling a bottle. The results will show the development during the initial days of use of the project in the shopping centers Plaza Norte and Mega Plaza; which at the same time will show the social interest of participation in the mentioned project.
\end{abstract}

Key words : Balsamiq Mockups, Environmental Pollution, Recycling System.

\section{INTRODUCTION}

The high consumption of plastic bottles has a variety of uses that has caused the number of bottles to increase every day over the years [1], [2]; however, although the plastic used serves the daily needs of a large part of the population, it is an environmental problem that has been identified due to the constant disposal of plastic bottles [3]. However, it is not only the excessive use of plastic that affects the environment, but also the fact that people throw them away carelessly, such as when throwing their bottles in the surroundings such as buses, parks, streets, rivers, beaches, etc.; which leads to predict that by 2050 there will be more plastic than fish in the oceans [4]. Another example of bad plastic disposal practice is that people burn 8-9 million tons of plastic waste. This leads to 62 cubic meters of methane, which is equivalent to one ton of carbon dioxide $(\mathrm{CO} 2)$ [5]. This underlines the vitality of a system that can contribute to recycling in terms of reducing plastic waste [6], [7].

In this methodology we developed Balsamiq Mockups, a tool to create prototypes of Web Interface and Mobile Application to simulate our recycling system [8], [9],[10].This Balsamiq Mockups methodology is used to develop an easy-to-use and fast web site and mobile application simulation, useful to communicate ideas [11]-[13].
The first stage of this work is the design of the web page, where the user can register and enter the page with the account already created, to finally enter the data of the bottle itself. After that, the second phase will seek to make our mobile application where the user will proceed to enter with the account registered by the website, and be able to see the points earned by each recycling made by the user and the benefits obtained. Finally, the user will be able to use his/her benefit by means of a QR code that will be served by the authorized Supermarket or Cinema; this process to promote the use of the application through previously established collaborations.

The objective is to reduce the environmental pollution that exists in our country by motivating users with a Recycling System that will benefit both our environment and the user, who will get discounts in supermarkets and cinemas, at the same time that the brands that commit to this social responsibility impulse will get more acceptance [14], [15]. The present work is structured as follows: Section 2 will describe in detail the methodology used for the design of the system. In section 3, the application of the web system is presented. Section 4 will show the results obtained and will discuss them and finally, section 5 will present the conclusions.

\section{METHODOLOGY}

The following is the Balsamiq Mockups 3 methodology to simulate our system in which a Web Interface will be developed to create a user account and be able to register the data of each recycled bottle with the objective of generating scores. After that, the Mobile Application will be used so that the user can use their points for recycling, since with this application they will be able to exchange their discounts in pre-established supermarkets and movie theaters.

The tools and languages that will be used to develop the system will also be discussed.

\subsection{Balsamiq Mockups 3}

Balsamiq Mockups is a free tool that allows us to design interfaces quickly and easily [16]. This is widely used as a prototyping tool, since it has various components that adjust to the needs of the application to be developed [17]. Therefore, it is highly recommended for the design of prototypes such as the Web Interface or the Mobile Application [18][19]. 


\section{A. Phase 1: Web Interface}

As a first step, the Balsamiq Mockups 3 method will be used to make a prototype of our "RecyclingBottlePeru" website. Also, the user and bottle registration will be designed, this method will be created using the container browser, text, icons, buttons, combo box, check box, link, text entry, date selector and alert box.

\section{B. Phase 2: Mobile Application}

As a second step, the prototype design will be created in Balsamiq Mockups to simulate the Mobile Application "RecycleBottlePeru" in order to design the redemption of your discounts, this method will be created from the design from the perspective of an iPhone and will have content such as text, icons, buttons, images, link and text input.

\subsection{Tools and Languages to Develop the Recycling System}

Below the tools and languages that will be used for the development of our website and mobile applications will be discussed.

\section{A. Sublime text 3}

It is a multi-platform code editor that allows us to work with several types of programming language, it is used to edit and program web pages [20][21].

\section{B. $P H P$}

With PHP (Hypertext Preprocessor) this project will be developed, it is an open source scripting language, easy to learn and works perfectly with the MySQL database, it is also very popular for web developers [22].

\section{C. $M y S Q L$}

MySQL is a popular database management, which implementation is fast, simple and easy to install. MySQL is closely associated to create interfaces with various types of language including PHP, Python and .NET; it will serve to manage our record of recycling bottles of each user [23].

\section{Android Studio}

It is a main tool of Android, in charge of developing an Application. It allows to be developed in code or also in a mobile or virtual device and is much related to the Java language or XML [24].

\section{E. Java}

Java is an object-oriented programming language, has a high level, this language does not allow writing insecure code. As it can be a risk its main basic components are the creation of classes, interfaces and packages [24][25].

\section{CASE STUDY}

\subsection{Phase 1: Web Interface}

As previously mentioned, the initial design will be the representation of the home page of the website, in which the user can register (as shown in Figure 1).

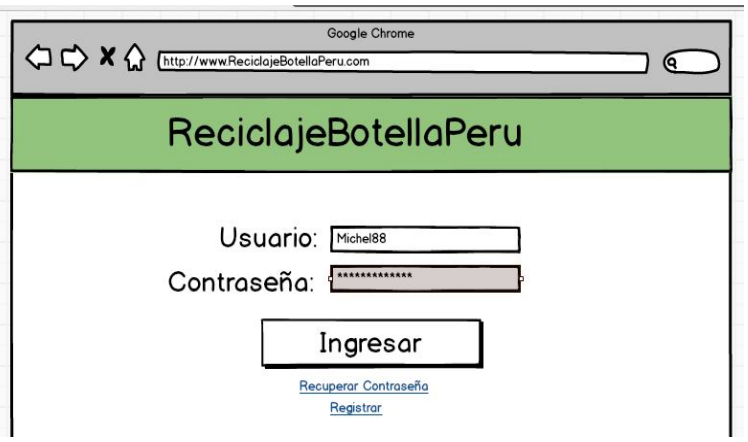

Figure 1:Home Screen of RecycleBottlePeru

In case the user doesn't have an account he or she will press the "Register" button and a confirmation screen will appear as shown in Figure 2.

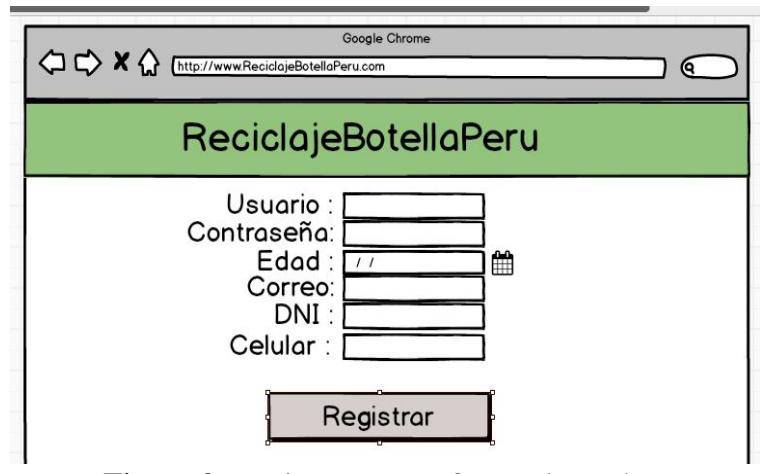

Figure 2: Register screen of RecycleBottlePeru

Furthermore, in case the user has forgotten his password, the button "Recover password" will be pressed, where the user will have to place the account's e-mail so that a confirmation message is sent to the registered account, as shown in Figure 3.

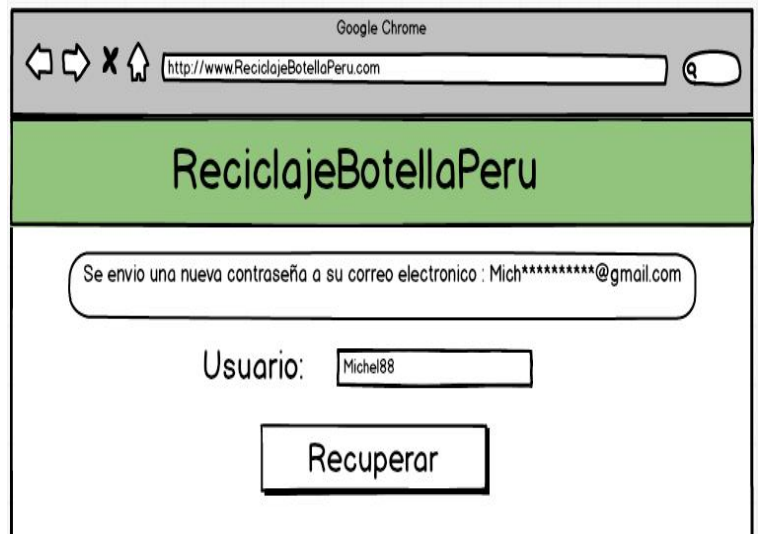

Figure 3: Recover password screen of RecycleBottlePeru

When the user has registered in their account, a new screen will be opened in which the user will proceed to register the discarded bottle, placing the barcode of the bottle and selecting the brand of the bottle that is entering as shown in Figure 4. 


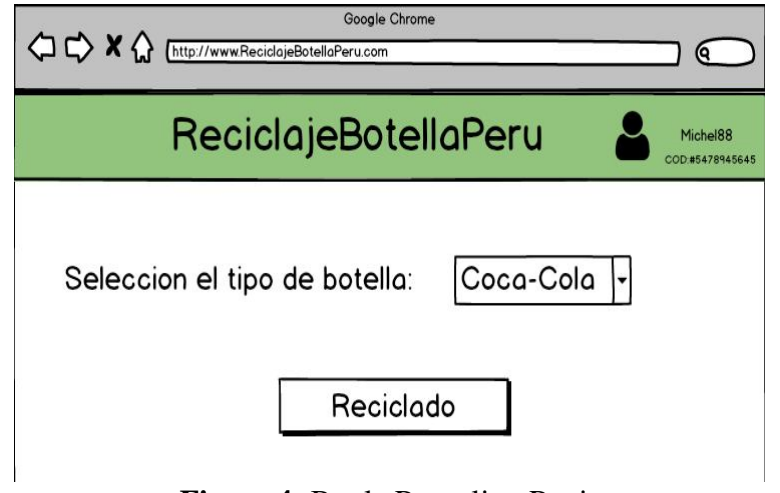

Figure 4: Bottle Recycling Register

For each bottle recycled by the user, points will be accumulated so that the user can exchange them by going to the establishment of their preference. If the user wants to use his exchange of points, he will use the Mobile Application to see what benefits he would get for the points acquired up to that moment.

\subsection{Phase 2: Mobile Application}

When the user is able to complete his data on the website, he will have to $\log$ in with his registered account from a smartphone (as shown in Figure 5).

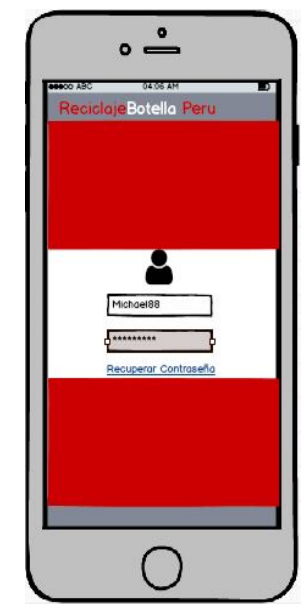

Figure 5: Login screen of RecycleBottlePeru

Once the user is logged in, the accumulated points will appear and show the benefits of different brands such as:

a) Discounts at CineMark.

b) Discounts at Cineplanet.

c) Discounts on products at PlazaVea Supermarket.

d) Discounts on products at Tottus Supermarket.

If the user decides to access the benefits, he must select the establishment of his preference and select the offer of his interest as shown in Figure 6.

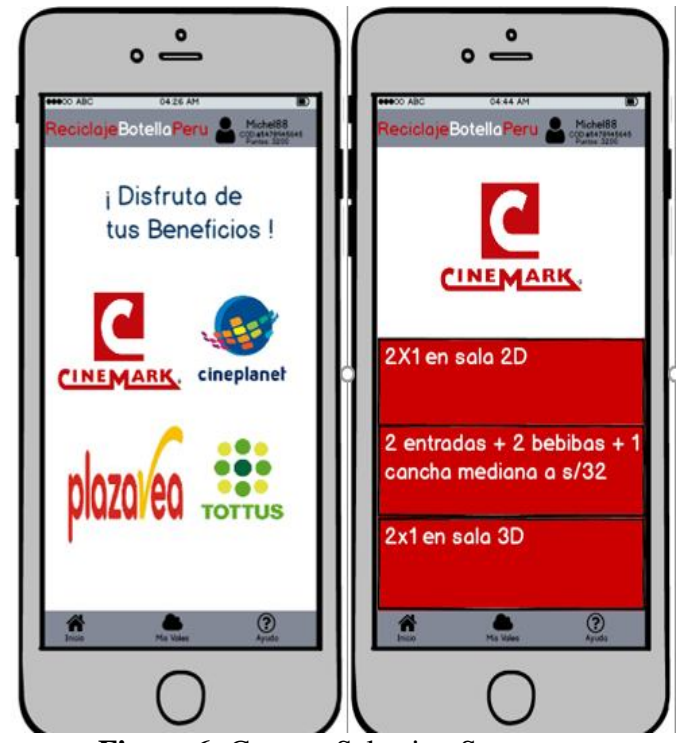

Figure 6: Coupon Selection Screen

When the user has selected a coupon, the details and how many points have to be spent to get that discount will be displayed. If the user has the required amount of points, he will proceed to redeem them by clicking on the "Claim Now" button, at the end of which a QR Code will appear as shown in Figure 7.

The user will go to the selected movie theater or store and with the QR Code generated he will be able to access the discounts or promotions.
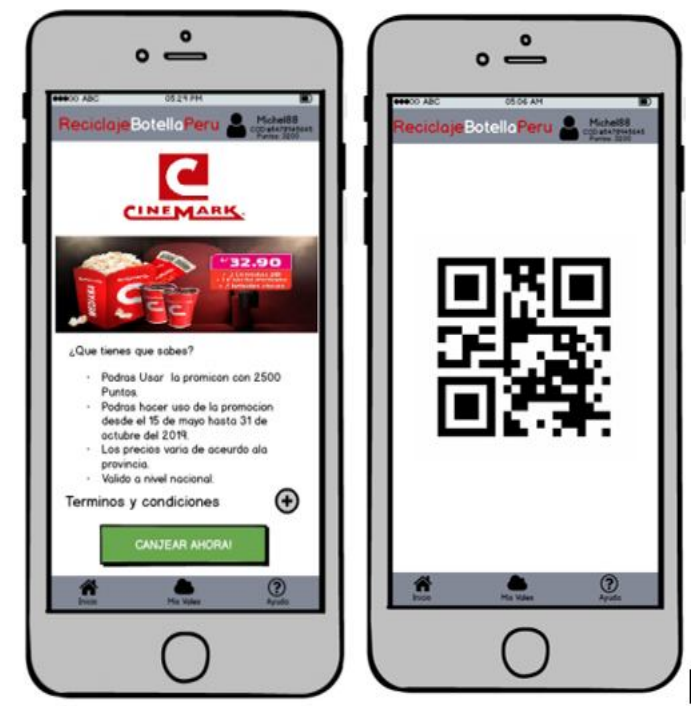

Figure 7: Exchange of coupons in the mobile application

\section{RESULTS AND DISCUSSION}

This section shows all the results of the application and operation of the mentioned software in the shopping centers of North Lima, Peru.

\subsection{About the Case Study}

A. Results of the web system

Resulting data is presented in Table 1. 
Alexi Delgado et al., International Journal of Emerging Trends in Engineering Research, 8(6), June 2020,2724 - 2729

Table 1: Results of the web system "RecyclingBottlePeru"

\begin{tabular}{|c|c|c|c|c|}
\hline Day & $\begin{array}{c}\text { Shopping } \\
\text { Center }\end{array}$ & $\begin{array}{l}\mathbf{N}^{\circ} \text { of } \\
\text { Users }\end{array}$ & Bottles & Brands \\
\hline \multirow{2}{*}{1} & Mega Plaza & 37 & 41 & $\begin{array}{c}\text { CocaCola: } 12 \\
\text { Fanta:5 } \\
\text { PerúCola:4 } \\
\text { IncaKola:6 } \\
\text { Cielo: } 10 \\
\text { San Luis:3 } \\
\text { Otros: } 1\end{array}$ \\
\hline & Plaza Norte & 39 & 46 & $\begin{array}{c}\text { CocaCola:15 } \\
\text { Cielo:5 } \\
\text { San Mateo:4 } \\
\text { Perú Cola:3 } \\
\text { Inca Kola:12 } \\
\text { Cifrut:3 } \\
\text { Otros:4 } \\
\end{array}$ \\
\hline TOTAL: & & 76 & 87 & \\
\hline
\end{tabular}

From the above data, we have obtained the following:

a) This recycling system was successfully applied in the shopping centers of North Lima (Mega Plaza and Plaza Norte).

b) We obtained the first result on day 1 .

c) In the Mega Plaza shopping center, we managed to have 37 registered users, and they have managed to discard 41 plastic bottles.

d) In the Plaza Norte shopping center, we managed to have 39 registered users, and they have discarded 46 plastic bottles.

e) According to the results of day 1, we reached 76 users in which we have recycled 87 bottles each day.

\section{B. Points score for Recycled Bottles}

Resulting data is presented in Table 2.

Table 2: Points score obtained by bottles collected amount

\begin{tabular}{|c|c|}
\hline Bottles collected amount & Score obtained \\
\hline 1 to 3 & 40 \\
\hline 4 to 6 & 80 \\
\hline 7 to 10 & 120 \\
\hline 11 to 14 & 200 \\
\hline 15 a 20 & 300 \\
\hline
\end{tabular}

From the previous Table, the following is considered:

a) If a user introduces 1 to 3 recycled bottles per day he will get 40 points.

b) If a user introduces 4 to 6 recycled bottles per day he will get 80 points.

c) If a user enters 7 to 10 recycled bottles per day he will get 120 points.

d) If a user enters 11 to 14 recycled bottles per day, they will get 200 points.

e) If a user enters 15-20 recycled bottles per day, they will earn 300 points.

f) If a user enters more than 20 bottles, he will get 300 points.

\section{Results of the Mobile Application}

Resulting data is presented in Table 3.

Table 3: Ranking of the mobile application "RecyclingBottlePeru"

\begin{tabular}{|c|c|c|c|c|}
\hline Rank & Users & Code & $\begin{array}{c}\text { Accumulated } \\
\text { Points }\end{array}$ & $\begin{array}{c}\text { Points } \\
\text { Used }\end{array}$ \\
\hline 1 & Martinez54 & 1987924873 & 200 & 0 \\
\hline 2 & Luis95 & 1978945645 & 120 & 0 \\
\hline 3 & Soledad445 & 1921479321 & 120 & 0 \\
\hline 4 & Isidro77 & 1974752111 & 120 & 0 \\
\hline 5 & Gian632 & 1917486321 & 80 & 0 \\
\hline 6 & Michel22 & 1938723645 & 80 & 0 \\
\hline
\end{tabular}

\subsection{About the Methodology}

\section{A. Advantages}

It is a fast access and user friendly program; to acquire it, it is enough to download it since it is a free program that allows to illustrate different prototypes or model designs for a better visualization of the project in execution. This function allows you to guarantee a model that meets the needs of the project in a structured, integrated and organized way through the exercise of dragging and dropping the different elements to create the final set, allowing you to modify any previous stage.

\section{B. Disadvantages}

On the other hand, while it shows a lot of benefits, some of the disadvantages of the platform are that some of the tools and components are not completely finished, it is also necessary to mention that a better precision system adjustment could be incorporated to obtain better results.

\section{Comparison}

There are a variety of methods to solve the situation that afflicts the environment. Therefore, a brief comparison will be made with an article published in a conference in Taoyuan, Taiwan [26], which sought to create a robot that would collect discarded products and place them in the corresponding recycling container through machine learning.

However, it should be noted that human participation in this study has been delegated. For this reason, it is considered that, although it is an innovative idea, it should promote social awareness through human participation by driving it through different motivations, as this study does not only through rewards but also by being available to anyone who has a smartphone. 


\section{CONCLUSION}

The application of the developed web system will help to improve the environment, reducing plastic waste and constantly promoting recycling. In the case study we defined the design of the web system that will serve as a model for the control of plastic bottle waste and the mobile application that will benefit users who recycle constantly.

The Balsamiq Mockups methodology supported us with the development of the web and mobile design, which shows its wide viability to design interface mockups in contexts like the present.

It is recommended to consider in the future for the implementation of the present artificial intelligence system to make a faster and more interactive recycling of plastic bottles through the motivation of users. Likewise, the possibility of expanding the horizons of the present and including different types of material for a greater impact is emphasized.

\section{REFERENCES}

[1] P. Dhulekar, S. T. Gandhe, and U. P. Mahajan, "Development of Bottle Recycling Machine Using Machine Learning Algorithm," 2018 Int. Conf. Adv. Commun. Comput. Technol. ICACCT 2018, pp. 515-519, 2018.

https://doi.org/10.1109/ICACCT.2018.8529483

[2] G. Gourmelon, "Global Plastic Production Rises, Recycling Lags | Worldwatch Institute," WorldWatch Inst., pp. 1-7, 2015.

[3] S. G. Howell, "A ten year review of plastics recycling," J. Hazard. Mater., vol. 29, no. 2, pp. 143-164, 1992.

https://doi.org/10.1016/0304-3894(92)85066-A

[4] L. Hornak, "Will There Be More Fish or Plastic in the Sea in 2050?," BBC News, 2016.

[5] V. Duong, A. Ahmed, and O. Farook, "A model template green environment initiative for recycling plastic bottles with progressive entrepreneurship partnership," PICMET 2018 - Portl. Int. Conf. Manag. Eng. Technol. Manag. Technol. Entrep. Engine Econ. Growth, Proc., pp. 1-5, 2018.

[6] M. Sejera, J. B. Ibarra, A. S. Canare, L. Escano, D. C. Mapanoo, and J. P. Suaviso, "Standalone Frequency Based Automated Trash Bin and Segregator of Plastic Bottles and Tin Cans," IEEE Reg. 10 Annu. Int. Conf. Proceedings/TENCON, pp. 2370-2372, 2017.

[7] M. F. Karin, K. S. Noor, and H. U. Zaman, "Hardware based design and implementation of a bottle recycling machine using FPGA," Proc. - 2016 IEEE Conf. Syst. Process Control. ICSPC 2016, no. December, pp. 43-46, 2017.

[8] J. M. Rivero, G. Rossi, J. Grigera, E. Robles Luna, and A. Navarro, "From interface mockups to Web application models," in Lecture Notes in Computer Science (including subseries Lecture Notes in Artificial Intelligence and Lecture Notes in Bioinformatics), 2011, vol. 6997 LNCS, pp. 257-264. https://doi.org/10.1007/978-3-642-24434-6_20
[9] A. Delgado, H. Chanamoth, A. Arias, and C. Carbajal, "Improving logistic management in a mass consumption distributor by web system design," in IEEE CHILEAN Conference on Electrical, Electronics Engineering, Information and Communication Technologies, CHILECON 2019, 2019.

[10] A. Delgado and H. Flor, "Selection of the best air purifier system to urban houses using AHP," in 2017 CHILEAN Conference on Electrical, Electronics Engineering, Information and Communication Technologies, CHILECON 2017 - Proceedings, 2017, vol. 2017-Janua.

[11] S. Rethinasamy et al., "Students' Learning Preferences of English for Academic Purposes - A KUiTTHO Affair," Br. J. Educ. Technol., vol. 8, no. 1, pp. 52-60, 2013.

[12] I. Bouchrika, L. Ait-Oubelli, A. Rabir, and N. Harrathi, "Mockup-based navigational diagram for the development of interactive web applications," in ACM International Conference Proceeding Series, 2013, pp. 27-32. https://doi.org/10.1145/2503859.2503864

[13] A. Delgado and J. Sosa, "Mobile application design of geolocation to collect solid waste: A case study in Lima, Peru," 2019, pp. 1-4.

[14] C. Li, B. Zu, Z. Li, and L. Zhang, "Corporate social responsibility and social responsibility needs of stakeholders," in 2011 International Conference on Remote Sensing, Environment and Transportation Engineering, RSETE 2011 - Proceedings, 2011, pp. 192-196.

[15] Z. Bai and K. McMartin, "Corporate social responsibility: A new perspective for alleviating poverty while maximizing profits," in TIC-STH'09: 2009 IEEE Toronto International Conference Science and Technology for Humanity, 2009, pp. 827-830.

[16] A. Parra Urrea, "Especificación de requisitos de software para el sistema de ficha clínica del CECH," pp. 8-117, 2013.

[17] C. Mendoza-Santos and A. Delgado, "Web application design for the control process of public schools," Int. J. Emerg. Trends Eng. Res., vol. 8, no. 4, pp. 1289-1294, Apr. 2020. https://doi.org/10.30534/ijeter/2020/57842020

[18] L. Kascak, C. B. Rebola, R. Braunstein, and J. Sanford, "Mobile application concept development for remote patient monitoring," Proc. - 2013 IEEE Int. Conf. Healthc. Informatics, ICHI 2013, pp. 545-550, 2013.

[19] A. Delgado and I. Romero, "Applying the Grey Systems Theory to Assess Social Impact from an Energy Project," in 2018 IEEE XXV International Conference on Electronics, Electrical Engineering and Computing (INTERCON), 2018, pp. 1-4.

[20] F.Manuel, "Sublime Text, un sofisticado editor de código multiplataforma," Genbeta, 2012.

[21] A. Delgado, P. Montellanos, and J. Llave, "Air quality level assessment in Lima city using the grey 
clustering method," in IEEE ICA-ACCA 2018 - IEEE

International Conference on Automation/23rd Congress of the Chilean Association of Automatic Control: Towards an Industry 4.0 - Proceedings, 2019.

[22] S. Walia and S. Gill, "A Framework for Web Based Student Record Management System using PHP," Int. J. Comput. Sci. Mob. Comput. ISSN 2320-088X, vol. 3, no. 8, pp. 24-33, 2014.

[23] K. Y. Koo, N. De Battista, and J. M. W. Brownjohn, "SHM data management system using MySQL database with MATLAB and web interfaces," SHMII-5 2011 - 5th Int. Conf. Struct. Heal. Monit. Intell. Infrastruct., no. December, 2011.

[24] A. Khan, F. Bibi, M. Dilshad, S. Ahmed, Z. Ullah, and H. Ali, "Accident detection and smart rescue system using android smartphone with real-time location tracking," Int. J. Adv. Comput. Sci. Appl., vol. 9, no. 6, pp. 341-355, 2018.

[25] V. Bax, W. Francesconi, and A. Delgado, "Land-use conflicts between biodiversity conservation and extractive industries in the Peruvian Andes," $J$. Environ. Manage., vol. 232, pp. 1028-1036, Feb. 2019.

[26] Y. P. Liao, R. C. Lu, S. Y. Wu, P. E. Cheng, and G. C. $\mathrm{Xu}$, "The robot for recycling based on machine learning," 2018 Int. Autom. Control Conf. CACS 2018, pp. 1-6, 2019.

https://doi.org/10.1109/CACS.2018.8606758 